\title{
Design of Crude Palm Oil Monitoring System using Electrical Capacitance Tomography: A Conceptual Framework
}

\author{
H. L. M. Ameran ${ }^{\#, 1}$, E. J. Mohamad ${ }^{\#, 2}$, R. A. Rahim ${ }^{\#, 3}$, W.N.A. Rashid ${ }^{*}$ Z. Mansor ${ }^{+}$ \\ ${ }^{\#}$ Instrumentation and Sensing Technology (InSet), Department of Mechatronic and Robotic Engineering, Faculty of Electrical and Electronic \\ Engineering, Universiti Tun Hussein Onn Malaysia, 86400 Batu Pahat, Malaysia \\ E-mail: ${ }^{1}$ hanis.liyana@yahoo.com, ${ }^{2}$ elmy@uthm.edu.my, ${ }^{3}$ ruzairi@uthm.edu.my
}

*Faculty of Engineering Technology, Universiti Teknikal Malaysia Melaka, 76100 Durian Tunggal, Malaysia

Email:norhisyam@utem.edu.my

${ }^{+}$Department of Electrical Engineering, Politeknik Merlimau, 77300 Merlimau, Malaysia

Email:zulkifli@pmm.edu.my

\begin{abstract}
In Crude Palm Oil (CPO) milling operations, the oil flow that has gone through separation process must be tested for its purity as wastes (e.g. palm oil mill effluent, water, sludge) tend to get carried along the process pipeline. At present, this procedure usually takes up to 5 days as samples of the flow needed to be verified biologically for its composition. Electrical Capacitance Tomography (ECT) systems that are able to provide the cross-sectional images of a closed content has proven the possibility of monitoring the composition of CPO flow in online manner. ECT systems are also able to provide other crucial flow information such as its velocity and flow regime that could help in controlling the processes. In this paper, a brief literature review of existing ECT systems are presented, then a conceptual design for developing an ECT system for visualizing and measuring CPO flow are presented along with the decision process of choosing suitable technique and hardware types for the new ECT system for CPO monitoring. A preliminary simulation study of the capability of the designed system to reconstruct images of water-oil flow phantoms is also presented. The simulation results show that the designed system is capable of reconstructing phantom images with error lower than $30 \%$.
\end{abstract}

Keywords-Electrical Capacitance Tomography; flow measurement; water-oil flow

\section{INTRODUCTION}

Process tomography is a tomographic imaging technique that is able to provide cross-sectional images of the contents inside closed process pipes or reactors [1]. This technique is categorised into different system types where its difference depends on the type of sensors and principles used e.g. radiative [2]-[5], ultrasound [6], [7], ultrasonic [8]-[10], electromagnetic [11], [12], resistive [13]-[16] and capacitive sensors [17]-[20]. These different types of sensors provides different types of signal measurement which then will be processed and manipulated to provide concentration distribution of the materials inside the pipe. The materials' concentration distribution is then used to reconstruct images that resembles pipe's contents. Process tomography is a powerful tool especially for process engineer as it can provide crucial flow information such as flow's concentration profile and velocity profile without the need to physically dissect the pipelines or disrupt the processes [21]. The obtained flow information can greatly aide in controlling process flow e.g. regulate an optimum flow speed, early detection of flow malfunction.

Electrical Capacitance Tomography (ECT) system is a type of process tomography where its principle is to measure the permittivity of materials inside the pipe. Electrodes are placed around the pipe and capacitance values between different electrode pairs are measured. The capacitance values differs in accordance to the permittivity value of each dielectric material, thus ECT system is reliable for differentiating materials of the pipe's content and suitable for measuring multiphase flows [22]. ECT systems also offers many other advantages such as robustness against environmental noise and high measurement speed. ECT systems have been successfully developed and installed in various industrial applications [23]; oil pipelines [21], [24], 
[25], chemical applications [26], [27], fluidized beds [28][30], pneumatic conveying and trickle bed reactors [31].

For an ECT system, its performance greatly depends on the number of measured capacitance values that effects the image resolution, as well as the signal processing speed [23]. Thus, a thorough literature study is crucial in order to select the most suitable technique and hardware for the ECT system. In literature, the highest reported speed for a 16electrodes ECT system is $200 \mathrm{fps}$ with a standard deviation of 0.00018 and $79.8 \mathrm{~dB}$ signal-to-noise ratio (SNR) [32].

In this paper, the design process of developing a 16electrodes segmented ECT system for monitoring Crude Palm Oil (CPO) multiphase flow with reconfigurable controller board is presented. In CPO milling operations, the oil flow that has gone through separation process must be tested for its purity as wastes (e.g. palm oil mill effluent, water, sludge) tend to get carried along the process pipeline. At present, this procedure usually takes up to 5 days as samples of the flow needed to be verified biologically for its composition [33]-[35]. ECT's ability to reliably visualise multi-phase flow can help in reducing the production time of CPO. A preliminary simulation study of the designed system in reconstructing images of different water-oil flow phantoms is also described.

\section{MATERIAL AND METHOD}

In this section, we discuss the design process of developing ECT system for visualising CPO flows. In general, an ECT can be divided into three main parts: 1) sensing system; 2) data control and acquisition system; and 3) image reconstruction system [36] as depicted in Fig. 1.

In most of the existing ECT systems, the sensing system comprises of electrodes that can alternatively act as sensor source and detecting sensor. The number of electrodes varies from $8,12,16$ or 32 . Behind these sensing electrodes are capacitance measurement circuits that could measure capacitance values between different electrode pairs. In order to retrieve capacitance measurements, the electrodes will act alternatively as the source and detecting sensor. The source electrode receives an excitation signal from a signal generator and the detecting electrode will act as capacitive probe. The measurement data is then conditioned, filtered and amplified before transformed into digital form.

The source/detector mode of each electrode is controlled by the data control and acquisition system. The digital data will be traditionally transferred to a PC where the image reconstruction algorithm will be performed and displayed.

\section{A. Electrode Number Selection}

An ECT is comprised of a number of electrodes. Reported ECT system is mostly comprised of 8,12 or 16 electrodes. The size of each electrode is seen to decrease relatively to the growing number of ECT sensor electrode from 8, 12, 16 or larger.

A good compromise between image resolution and data acquisition speed is needed in order to select the suitable number of electrodes. A smaller number of electrodes means a reduced number of data acquisition channel thus simultaneously produces a faster data acquisition speed. However, it also means that less measurement data is retrieved which directly results in lower image resolution. Furthermore, if the number of electrodes is too high, the system's complexity as well as its cost will increase [37].

For a system with $N$ number of electrodes, there are $N(N-$ 1) $/ 2$ single electrode pairs which is also the number of independent capacitance measurement [38]. For this project, the electrodes are mounted around a $110 \mathrm{~mm}$ diameter pipe and the number of electrodes chosen is 16 and the number of independent capacitance measurement that will be provided is 120 .

\section{B. Capacitance Measurement Circuit}

Although there exists many capacitance measurement circuits in the industry, measuring capacitance for an ECT system is known to be a difficult task as the circuit must: have high sensitivity for detecting very small capacitance change; and be immune to stray capacitance [39].

In [37], a comparison of capacitance measurement circuits for ECT which are charge/discharge, AC-based, impedance analyzer based. However, it is found that the charge/discharge and AC-based circuits are most suitable for the use of ECT systems [39].

A charge/discharge circuit offers simplicity and low cost as its advantage. In addition, this circuit is stray-immune, has high measurement resolution (charge injection does not affect the measurement) and high data acquisition rate (no filter is used) [18]. However, the coupling capacitance of CMOS switches which is relatively much larger than the measured capacitance will affect the measurement precision. In order to correct this, a careful selection of charge injection needed to be made.
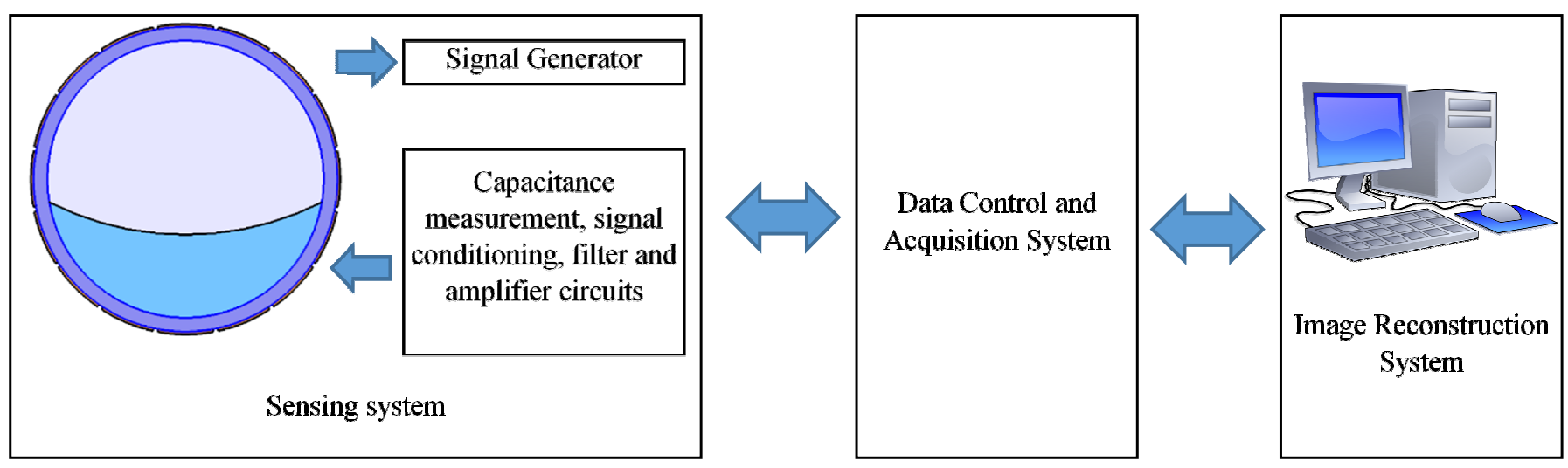

Fig. 1 Schematic representation of a typical ECT system 
Fig. 2 shows an AC-based circuit. $V_{i}(t)$ is sine-wave voltage source, $C_{x}$ is the measured capacitance, $C_{f}$ and $R_{f}$ are op-amp feedback capacitance and resistance respectively. The output of the circuit $V_{o}(t)$ is obtained from equation:

$$
V_{0}=\frac{j \omega C_{x} R_{f}}{j \omega C_{f} R_{f}+1} \cdot V_{i}
$$

Where $\omega$ is the angular frequency of the sine-wave voltage. The output of an AC-based circuit is an AC signal that is proportional to the measured capacitance in magnitude. The output AC signal is conditioned in order to produce a DC signal that represents the measured capacitance values. In order to simplify (1), a high frequency source signal is needed as when $\left|j \omega C_{x} R_{f}\right|>>1$, becomes

$$
V_{0}=-\frac{C_{x}}{C_{f}} \cdot V_{i}
$$

The excitation frequency is limited by the op-amp bandwidth. In [40], it is pointed that the frequency of source signal can be as high as $1 \mathrm{MHz}$. Although this circuit is more complex, it offers high SNR than the charge/discharge circuit. According to [38] and [41], the stray capacitances $C_{s 1}$ and $C_{s 2}$ are negligible making the AC-based circuit stray immune [37]. Thus, for this research, the AC-based capacitance measurement circuit is chosen.

\section{Signal Conditioning Circuits}

The input signal $V_{i}(t)$ of the capacitance transducer is the sine wave generated by the function generator. Thus, the output signal $V_{o}(t)$ is a sine wave as well, whose amplitude depends on the unknown measured capacitance $C_{x}$. To obtain the value of this amplitude, the AC-to-DC converter is used where it is either a rectifier or a phase-sensitive demodulator (PSD) circuits.

In the current existing project, an absolute value circuit is used as AC-to-DC converter where its output is directly connected to the microcontroller whose internal analog-todigital converter (ADC) provides a digitized measurement for both $V_{i}(t)$ and $V_{o}(t)$ amplitudes from which the final value of the inter-electrode capacitance can be obtained. Therefore, the combination of classic AC-based capacitance transducer and absolute value circuit converter results in a stage that provides a DC output signal a direct relation to the unknown capacitance $C_{x}$, which can be easily digitalized and processed by the microcontroller.

The absolute value circuit is subsequently combined with the first order low-pass filter to reduce noise and to get a clean DC output from the AC input voltage. To ensure that the signal voltage is in a measurable range, it must be amplified, thus a high-speed programmable gain instrumentation amplifier, PGA206 IC, is applied in the system [42], [43].

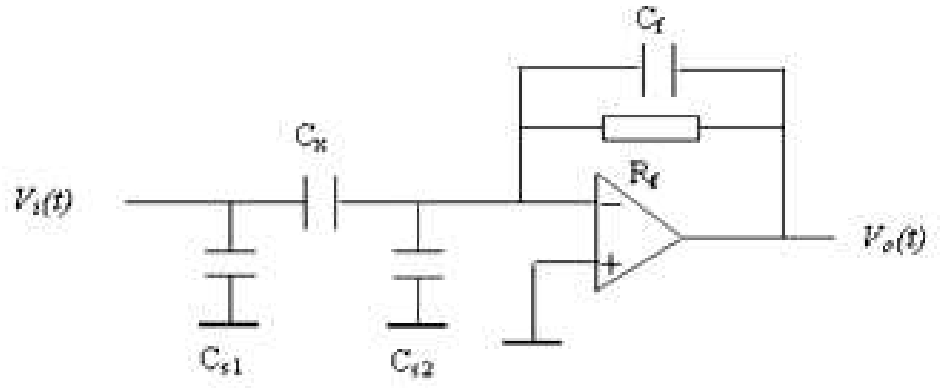

Fig. 2 AC-Based capacitance measuring circuit

\section{Data Control and Acquisition System}

In the current ECT system, a main control unit is used to synchronize all the operations on collecting measurement data and sending the data to a PC for image reconstruction. It is used to synchronize all the transmitted and received operations on sensor. The main controller unit consists of the microcontroller PIC18F4550, a function generator, a USB, and a switching circuit. It can collect the data of two-plane 16 electrodes (up-stream and down-stream ECT sensor plane) in parallel.

A total of 120 data are collected in each measurement cycle. Sending data to the PC in bulk is much faster than sending in byte. Thus, all the data are stored in memory before being sent to the computer for image reconstruction. Overall, the hardware is working standalone, which means that the main control unit oversees the whole process after receiving instructions from a host computer. The main control unit continuously controls the measuring operation, collecting data from electrode modules and sending data to the host computer for image reconstruction.

From literature, it is reported that the speed and accuracy of the system could be significantly improved by replacing microcontrollers with an FPGA as the control unit. The ECT system uses 16 electrodes that alternatively act as sensor transmitter and receiver, the possibility of doing parallel operations using FPGA will greatly reduce the excitation and measurement cycle time of the 16 sensors by a maximum factor of 16. The delay introduced in different analog and digital components mismatch could also be eliminated as the single FPGA processor will use a global clock cycle [44][46]. A comparison of the principal performance indicator of existing FPGA based ECT systems is depicted in Table 1.

TABLE 1

\begin{tabular}{|c|c|c|}
\hline Previous ECT system & SNR & $\begin{array}{l}\text { Frame rate } \\
\left(\text { frames s }^{-1}\right)\end{array}$ \\
\hline [47] 12-electrode sensor (2014) & $59.03 \mathrm{~dB}$ & 845 \\
\hline [48] 12-electrode sensor (2012) & N/A & 1000 \\
\hline [23] 12-electrode sensor (2011) & $60.3 \mathrm{~dB}$ & 1542 \\
\hline [45] 12-electrode sensor (2005) & N/A & 2439 \\
\hline [49]16-electrode sensor (2017) & N/A & 16949 \\
\hline [50]16-electrode sensor (2015) & N/A & 8475 \\
\hline [51] 16-electrode sensor (2011) & N/A & 300 \\
\hline [52] 16-electrode sensor (2007) & $60.4 \mathrm{~dB}$ & 1000 \\
\hline [32] 16-electrode sensor (2009) & $79.8 \mathrm{~dB}$ & 200 \\
\hline [53] 16-electrode sensor (2008) & $74 \mathrm{~dB}$ & 150 \\
\hline [54] 16-electrode sensor (2008) & $76 \mathrm{~dB}$ & 150 \\
\hline
\end{tabular}

PERFORMANCE COMPARISON OF FPGA BASED ECT SYSTEM 


\section{RESULT AND DISCUSSION}

A computational simulation software based on Finite Element Method (FEM), COMSOL Multiphysics is used in this project. FEM quantifies the sensor geometry into smaller elements and calculate the corresponding measurements of each finer elements. In order to analyse the capability of the designed system in the chosen dimension and sensor parameters, a simulation study on the system's reaction when source electrode is injected with excitation signal were done. The signal received at the receiving electrodes is also recorded.

The ECT system were first modelled using COMSOL Multiphysics in electrostatics module and stationary study mode. The ECT model (

Fig. 3) were drawn in accordance to the real hardware dimension and the parameters chosen are: 16 electrodes, 100 $\mathrm{mm}$ inner pipe diameter, $110 \mathrm{~mm}$ outer pipe diameter, 20 $\mathrm{mm}$ electrode width and $22.5^{\circ}$ angular distance between electrodes. The material of the electrode sensors is copper and the material of the pipe is acrylic plastic.

In the beginning, we simulate the system's response when one electrode is injected with excitation source of $5 \mathrm{~V}$. Three phantom flows of water (relative permittivity of 80.8) and oil (relative permittivity of 3 ) were used where the phantoms are: 1) pipe is filled with water (Fig. 4); 2) pipe filled with water and an oil bubble of $10 \mathrm{~mm}$ diameter (Fig. 5); and 3) pipe filled with water and an oil bubble of $20 \mathrm{~mm}$ diameter (Fig. 6). These phantoms of water and oil were chosen to represent the liquid waste in $\mathrm{CPO}$ flow.

From Fig. 5 and Fig. 6 it can be observed that the electric field lines (in white) change in the presence and in accordance of the oil bubble. The electric field lines in Fig. 4 follow a straight path from the exciting electrode to all receiving electrodes as there are no difference of permittivity value across the pipeline. In Fig. 5 and Fig. 6, the electric field lines curve around the oil bubble in accordance to its position and size as there are difference in permittivity value between oil and water.

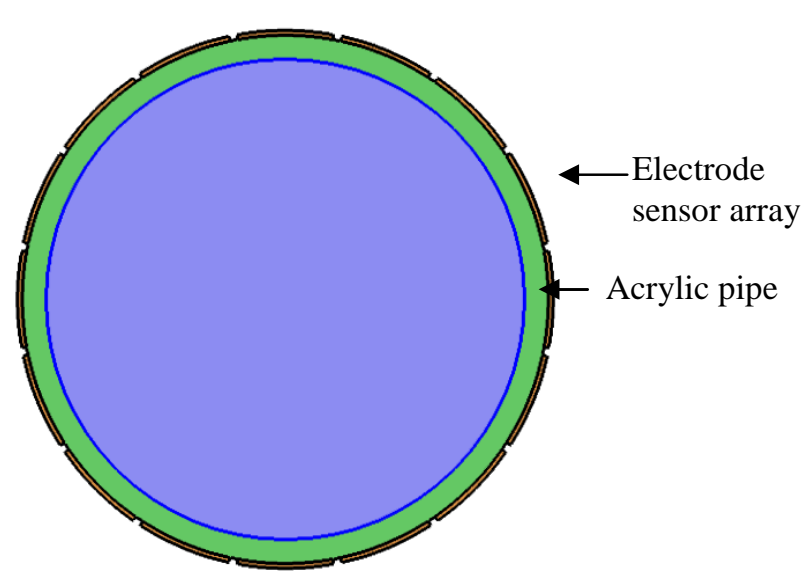

Fig. 3 ECT sensor model
Surface: Electric potential (V) Streamline: Electric field

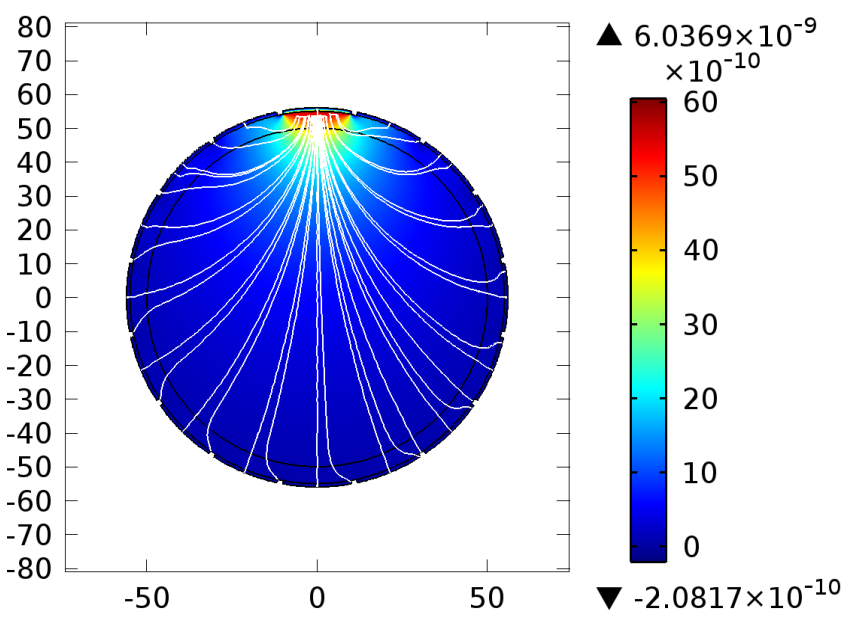

Fig. 4 Potential distribution and electric field lines of ECT system when the pipeline is filled with water

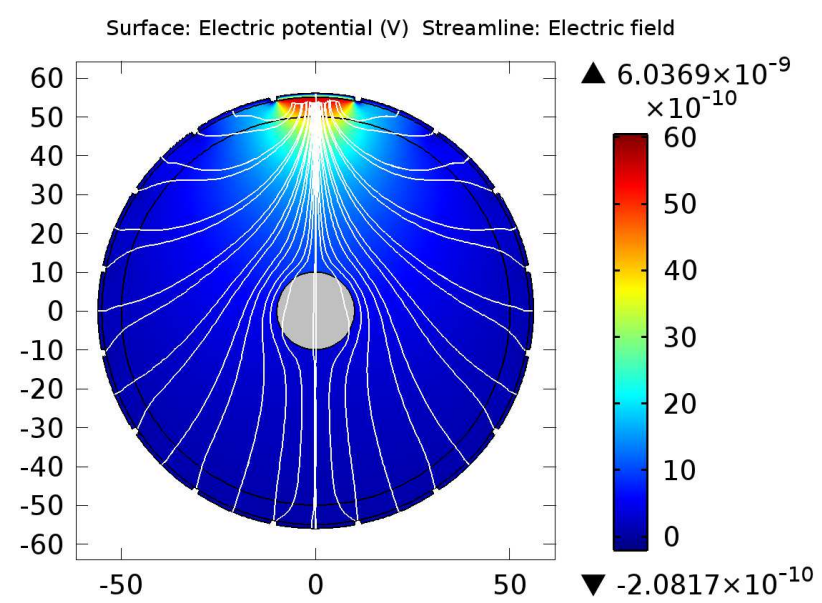

Fig. 5 Potential distribution and electric field lines of ECT system when the pipeline filled with water and contains oil bubble of diameter $10 \mathrm{~mm}$ in the pipe center (circle in gray color)

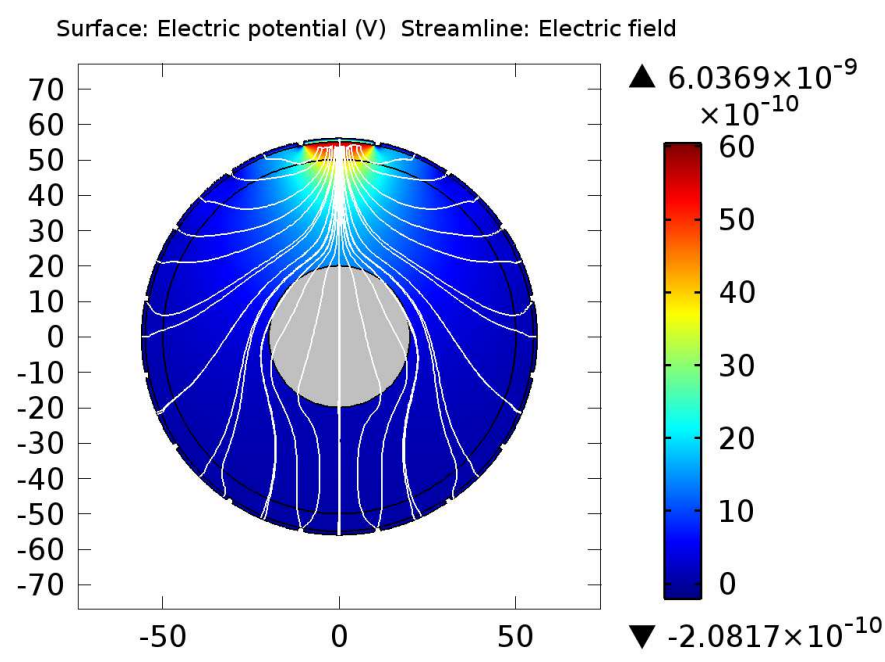

Fig. 6 Potential distribution and electric field lines of ECT system when the pipeline filled with water and contains oil bubble of diameter $20 \mathrm{~mm}$ in the pipe center (circle in gray color) 
In an ECT system, the excitation sequence as well as its frequency and voltage level influence the accuracy of the measurement [55]. In previous ECT system the excitation signal is a sine wave of $5 \mathrm{~V}$ peak-to-peak amplitude and 500 $\mathrm{Hz}$ frequency. However, when using FPGA as the controller, the excitation signal is limited to $3.3 \mathrm{~V}$ peak-to-peak amplitude. A simulation study of the ECT system using the new excitation signal is presented in this section in order to analyse the capability and performance of the FPGA based ECT system in measuring the capacitance value and reconstructing phantom images that were done using a Finite Element Method software named COMSOL Multiphysics and MATLAB.

Two phantoms of water and oil were created in COMSOL and reconstructed in MATLAB using Linear Back Projection (LBP) algorithm. The two phantoms were applied with the two voltage levels in order to see the performance of the system. Image error is calculated for each image using [56] where $g$ is the pixel percentage representing high permittivity object:

$$
\text { error } \%=\frac{\left\|g-g_{\text {phantom }}\right\|}{g} \bullet 100 \%
$$

Table 2 shows the results of reconstructed images of different phantoms when $5 \mathrm{~V}$ and $3.3 \mathrm{~V}$ of excitation signals are applied. The error difference between both potential signals is less than $5 \%$ with $3.3 \mathrm{~V}$ signal providing more error. However, the error can still be considered low and tolerable. The error can be reduced by implementing a level converter between the FPGA and sensing module but the speed of the level converter needed to be chosen properly in order to maintain the high speed advantage provided by the FPGA controller.
Fig. 7 shows the capacitance measurements on each receiving electrodes (electrode 2 to electrode 16) when an excitation potential is applied at electrode 1 with two different voltages ( $5 \mathrm{~V}$ and $3.3 \mathrm{~V}$ ) in a water filled pipe. The measured capacitance when $3.3 \mathrm{~V}$ signal applied to the excitation electrode is lower than when $5 \mathrm{~V}$ voltage is applied. However, as stated in [55], the accuracy of the measurement does not only depends on the measured signal level but also to the uniform distribution of the signals. When $5 \mathrm{~V}$ signal is applied, the difference between the highest and the lowest signal received is $1.1 \mathrm{nF}$ meanwhile the difference between the highest and the lowest signal received when $3.3 \mathrm{~V}$ signal applied is $7.23 \mathrm{pF}$. This shows that even though the level of measurements received with $3.3 \mathrm{~V}$ signal is comparatively lower than $5 \mathrm{~V}$ signal, the uniformity of the signal distribution is still improved.

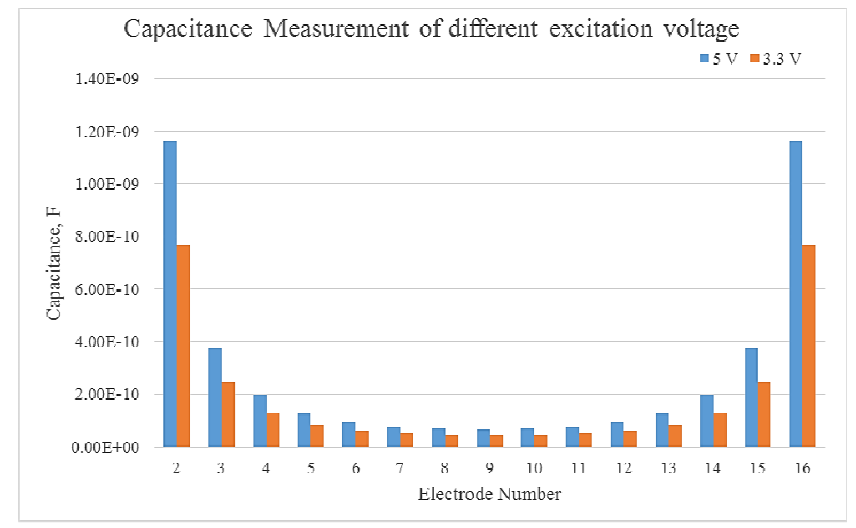

Fig. 7 Capacitance measurement on each electrode when electrode 1 is excited with $5 \mathrm{~V}$ (blue) and $3.3 \mathrm{~V}$ (orange)

TABLE 2

ReCONSTRUCTEd IMAges AND ERRor Percentage of WATER-Oil Phantoms

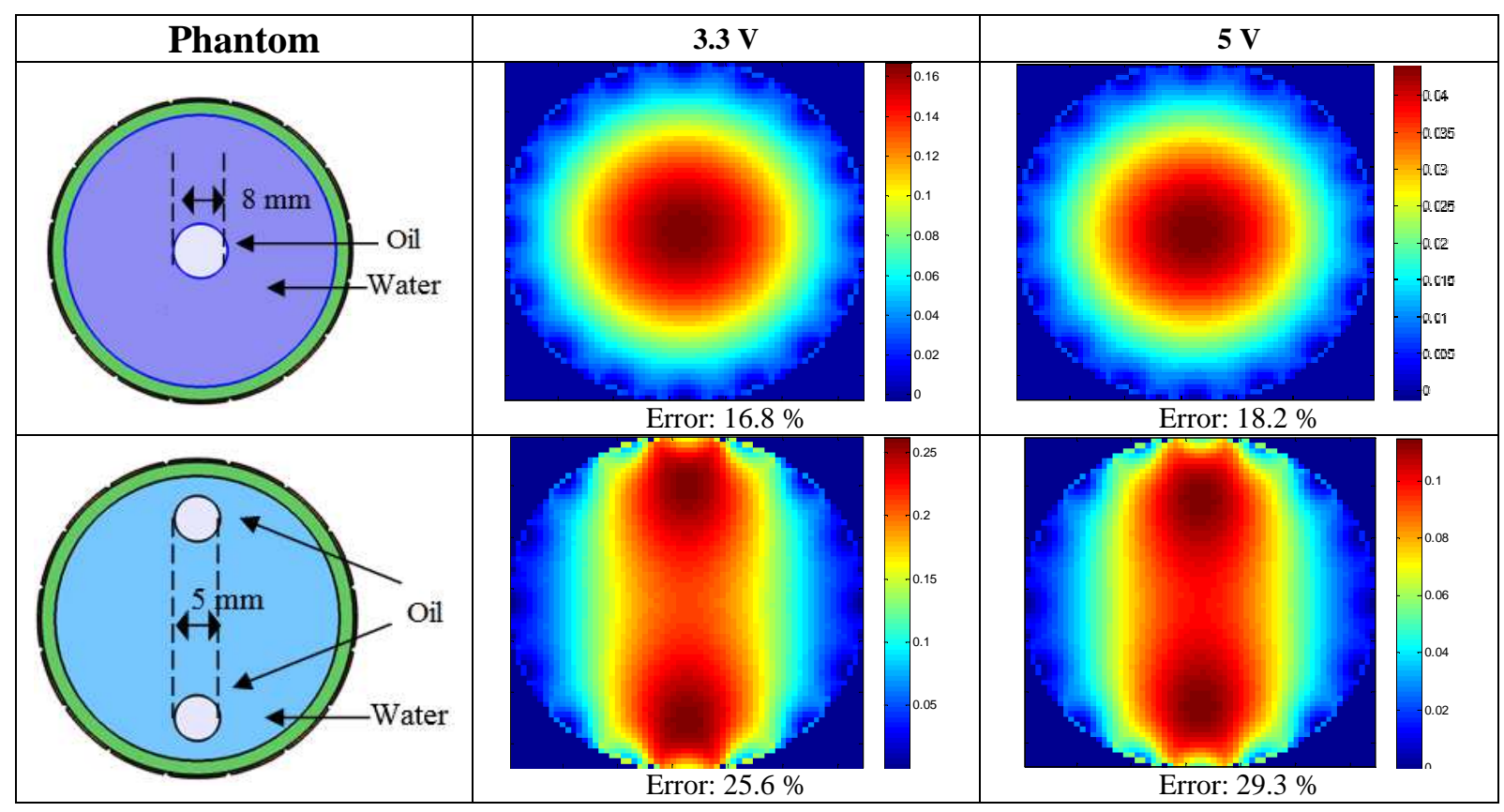




\section{CONCLUSION}

A conceptual design along with technique and hardware type selection for developing an ECT system for monitoring Crude Palm Oil are presented in this work. Preliminary results of ECT modelling were also presented and discussed. From the simulation study of designed system, it is observed that the system can perform in accordance to the principle of ECT system where it can differentiate materials of different permittivity values. The images reconstructed of the wateroil flow phantoms from the simulation study show error percentage of $30 \%$. In conclusion, the new design of ECT system is being considered to be implemented but the measurements level of the system needed to be improved with an additional level converter circuit.

\section{ACKNOWLEDGMENT}

The authors are grateful to the financial support from Biasiswazah Scholarship and Research \& Innovation Fund of Universiti Tun Hussein Onn Malaysia.

\section{REFERENCES}

[1] Gladden, L. F. Process Tomography: Principles, Techniques and Applications. Meas. Sci. Technol. Apr. 1997. 8(4).

[2] Hanus, R., Zych, M., Petryka, L., and Świsulski, D. Time Delay Estimation in Two-Phase Flow Investigation Using the $\gamma$-Ray Attenuation Technique. Math. Probl. Eng. 2014.

[3] Barthel, F., Bieberle, M., Hoppe, D., Banowski, M., and Hampel, U. Velocity measurement for two-phase flows based on ultrafast X-ray tomography. Flow Meas. Instrum. Dec. 2015. 46: 196-203.

[4] Schäfer, T., Bieberle, A., Neumann, M., and Hampel, U. Application of gamma-ray computed tomography for the analysis of gas holdup distributions in centrifugal pumps. Flow Meas. Instrum. Dec. 2015. 46: 262-267.

[5] Westman, E. C. Use of Tomography for Inference of Stress Redistribution in Rock. IEEE Trans. Ind. Appl. Sep. 2004. 40(5): 1413-1417.

[6] Xu, L. J. and Xu, L. A. Ultrasound tomography system used for monitoring bubbly gas/liquid two-phase flow. IEEE Trans. Ultrason. Ferroelectr. Freq. Control. 1997. 44(1): 67-76.

[7] Ming Yang, M., Schlaberg, H. I., Hoyle, B. S., Beck, M. S., and Lenn, C. Real-time ultrasound process tomography for two-phase flow imaging using a reduced number of transducers. IEEE Trans. Ultrason. Ferroelectr. Freq. Control. May 1999. 46(3): 492-501.

[8] Rahiman, M. H. F., Rahim, R. A., Rahim, H. A., Mohamad, E. J., Zakaria, Z., and Muji, S. Z. M. An investigation on chemical bubble column using ultrasonic tomography for imaging of gas profiles. Sensors Actuators B Chem. 2014. 202: 46-52.

[9] Rahim, R. A., Rahiman, M. H. F., Chan, K. S., and Nawawi, S. W. Non-invasive imaging of liquid/gas flow using ultrasonic transmission-mode tomography. Sensors Actuators, A Phys. 2007. 135(2): 337-345.

[10] Pusppanathan, M. J. et al. A Novel Electrical Cpacitance Sensor Design For Dual Modality Tomography Multiphase Measurement. $J$. Teknol. Oct. 2013. 64(5).

[11] Yu, Z. Z., Xu, L. A., Peyton, A. J., and Beck, M. S. Electromagnetic inductance tomography (EMT): sensor, electronics and image reconstruction algorithm for a system with a rotatable parallel excitation field. IEE Proc. - Sci. Meas. Technol. Jan. 1998. 145(1): 20-25.

[12] Leeungculsatien, T. and Lucas, G. P. Measurement of velocity profiles in multiphase flow using a multi-electrode electromagnetic flow meter. Flow Meas. Instrum. Jun. 2013. 31: 86-95.

[13] Abdul Wahab, Y. et al. Compatible Study on Utilizing Frequency for Non-Invasive Electrical Resistance Tomography Using COMSOL Multiphysics. J. Teknol. Apr. 2015. 73(6).

[14] Sharifi, M. and Young, B. Electrical Resistance Tomography (ERT) applications to Chemical Engineering. Chem. Eng. Res. Des. Sep. 2013. 91(9): 1625-1645.
[15] Tan, C. T. C. and Dong, F. D. F. Two-Phase Flow Measurement by Dual-Plane Ert System with Drift-Flux Model and Cross Correlation Thechnique. 2006 Int. Conf. Mach. Learn. Cybern. 2006.

[16] Aw, S. R., Rahim, R. A., Rahiman, M. H. F., Yunus, F. R. M., and Goh, C. L. Electrical resistance tomography: A review of the application of conducting vessel walls. Powder Technol. 2014. 254: 256-264.

[17] Mohamad, E. J. A Segmented Capacitance Tomography for Visualising Material Distributions in Pipeline Conveying Crude Palm Oil. Universiti Teknologi Malaysia. 2012.

[18] Yang, W. Q. Hardware design of electrical capacitance tomography systems. Meas. Sci. Technol. Mar. 1996. 7(3): 225-232.

[19] Firadus, A. and Meribout, M. A new energy aware embedded architecture for real-time Electrical Capacitance Tomography. 2013 4th Annual International Conference on Energy Aware Computing Systems and Applications (ICEAC). 2013. pp. 93-96.

[20] Li, Y. et al. Gas/oil/water flow measurement by electrical capacitance tomography. 2012 IEEE International Conference on Imaging Systems and Techniques Proceedings. 2013. p. 74001.

[21] Mohamad, E. J. et al. Segmented capacitance tomography electrodes: A design and experimental verifications. IEEE Sens. J. 2012. 12(5): 1589-1598.

[22] Abd Rashid, W. N., Mohamad, E. J., Abdul Rahim, R., Abdullah, J., and Mohmad Ameran, H. L. Electrical capacitance tomography: a review on portable ECT system and hardware design. Sens. Rev. Jan. 2016. 36(1): 64-70.

[23] Cui, Z., Wang, H., Chen, Z., Xu, Y., and Yang, W. A highperformance digital system for electrical capacitance tomography. Meas. Sci. Technol. May 2011. 22(5): 55503.

[24] Ismail, I., Gamio, J. C., Bukhari, S. F. A., and Yang, W. Q Tomography for multi-phase flow measurement in the oil industry. Flow Meas. Instrum. Apr. 2005. 16(2-3): 145-155.

[25] Zimam, M. A., Mohamad, E. J., Abdul Rahim, R., and Leow, P. L. Sensor Modelling For An Electrical Capacitance Tomography System Using COmsol Multiphysics. J. Teknol. 2011. 55(2): 33-47.

[26] Tapp, H. S., Peyton, A. J., Kemsley, E. K., and Wilson, R. H. Chemical engineering applications of electrical process tomography. Sensors Actuators B Chem. Jul. 2003. 92(1-2): 17-24.

[27] Liu, G., Lan, J., Cao, Y., Huang, Z., Cheng, Z., and Mi, Z. New insights into transient behaviors of local liquid-holdup in periodically operated trickle-bed reactors using electrical capacitance tomography (ECT). Chem. Eng. Sci. Jul. 2009. 64(14): 3329-3343.

[28] Wang, H. G. and Yang, W. Q. Measurement of fluidised bed dryer by different frequency and different normalisation methods with electrical capacitance tomography. Powder Technol. Apr. 2010. 199(1): 60-69.

[29] Warsito, W. and Fan, L.-S. Dynamics of spiral bubble plume motion in the entrance region of bubble columns and three-phase fluidized beds using 3D ECT. Chem. Eng. Sci. Nov. 2005. 60(22): 6073-6084.

[30] Dyakowski, T., Edwards, R. B., Xie, C. G., and Williams, R. A. Application of capacitance tomography to gas-solid flows. Chem. Eng. Sci. Jul. 1997. 52(13): 2099-2110.

[31] Zhu, K., Madhusudana Rao, S., Wang, C.-H., and Sundaresan, S. Electrical capacitance tomography measurements on vertical and inclined pneumatic conveying of granular solids. Chem. Eng. Sci. Sep. 2003. 58(18): 4225-4245.

[32] Huaxiang Wang, Shan Xin, and Xuehui Zhang. New progress of the digital electrical capacitanc e tomography system for gas/liquid two phase flow. 2009 IEEE International Workshop on Imaging Systems and Techniques. 2009. pp. 37-40.

[33] Mohamad, E. J., Rahim, R. A., Rahiman, M. H. F., and Muji, S. Z. M. Electronic Design of Portable ECT for Crude Palm Oil Quality Monitoring System. Int. J. Innov. Comput. Inf. Control. 2012. 8(1(B)): 867-893.

[34] Hidayati, J., Sukardi, Suryani, A., Fauzi, A. M., and Sugiharto Optimization of palm oil plantation revitalization in North Sumatera Indonesia. Int. J. Adv. Sci. Eng. Inf. Technol. 2015. 5(6): 460-468.

[35] Hermansah, Ermadani, Yulnafatmawita, Syarif, A., and Rusman, B. Optimizing utilization of palm oil mill effluent and its influences on nutrient availability and soil organic matter on ultisols. Int. J. Adv. Sci. Eng. Inf. Technol. 2017. 7(1): 257-262.

[36] Abdul Wahab, Y. et al. Non-invasive process tomography in chemical mixtures - A review. Sensors Actuators B Chem. Apr. 2015. 210: 602-617.

[37] Chen, D., Yang, W., and Deng, X. Comparison of three electrical capacitance tomography systems. 2010 IEEE International Conference on Imaging Systems and Techniques. 2010. pp. 57-62. 
[38] Yang, W. Q. and York, T. A. New AC-based capacitance tomography system. IEE Proc. - Sci. Meas. Technol. Jan. 1999. 146(1): 47.

[39] Baoliang Wang, Haifeng Ji, Zhiyao Huang, and Haiqing Li. A highspeed data acquisition system for ECT based on the differential sampling method. IEEE Sens. J. Apr. 2005. 5(2): 308-312.

[40] Pickup, E., Deloughry, R., and Hartley, T. Measurement of small capacitance changes for use in tomographic imaging. Proc. of European Although the charge/discharge ECT system is simple and Concerted Action on Process Tomography'95,. 1995. pp. 256-265.

[41] Yang, W. Q. Further developments in an ac-based capacitance tomography system. Rev. Sci. Instrum. 2001. 72: 3902-3907.

[42] Gamio, J. C., Yang, W. Q., and Stott, A. L. Analysis of non-ideal characteristics of an ac-based capacitance transducer for tomography. Meas. Sci. Technol. Aug. 2001. 12(8): 1076-1082.

[43] Yang, W. Q., Stott, A. L., and Gamio, J. C. Analysis of the effect of stray capacitance on an AC-based capacitance tomography transducer. IEEE Trans. Instrum. Meas. Oct. 2003. 52(5): 1674-1681.

[44] Czarnecki, P., Danko, L., and Szabatin, R. One channel capacitance tomograph with hardware implementation of image reconstruction algorithm. 2009 IEEE International Workshop on Imaging Systems and Techniques. 2009. pp. 242-246.

[45] Almashary, B., Qasim, S. M., Alshebeili, S., and Al-Masry, W. A. Realization of Linear Back-Projection Algorithm for Capacitance Tomography using FPGA. 4th World Congress on Industrial Process Tomography. 2005. pp. 88-93.

[46] Herdian, H., Muttakin, I., Saputra, A., Yusuf, A., Widada, W., and Taruno, W. P. Hardware implementation of linear back-projection algorithm for capacitance tomography. 2015 4th International Conference on Instrumentation, Communications, Information Technology, and Biomedical Engineering (ICICI-BME). 2015. pp. 124-129.

[47] Yang, C., Cui, Z., Xue, Q., Wang, H., Zhang, D., and Geng, Y. Application of a high speed ECT system to online monitoring of pneumatic conveying process. Measurement. Feb. 2014. 48: 29-42.
[48] Cui, Z., Wang, H., Yang, C., Zhang, D., and Geng, Y. Development and application of ECT digital system for online flow measurement. 2012 IEEE International Conference on Imaging Systems and Techniques Proceedings. 2012. pp. 599-604.

[49] Meribout, M. and Teniou, S. A Pipelined Parallel Hardware Architecture for 2-D Real-Time Electrical Capacitance Tomography Imaging Using Interframe Correlation. IEEE Trans. Very Large Scale Integr. Syst. Apr. 2017. 25(4): 1320-1328.

[50] Fajar Firdaus, A. and Meribout, M. A New Parallel VLSI Architecture for Real-Time Electrical Capacitance Tomography. IEEE Trans. Comput. Jan. 2016. 65(1): 30-41.

[51] Klos, M. and Smolik, W. T. Single channel electrical capacitance tomograph for dynamic process visualization. 2011 IEEE International Conference on Imaging Systems and Techniques. 2011. pp. 133-136.

[52] Zhang, X., Wang, H., Cui, Z., and Tang, L. A Novel ECT System Based on FPGA and DSP. Second International Conference on Innovative Computing, Informatio and Control (ICICIC 2007). 2007. pp. 510-510.

[53] Cui, Z., Wang, H., Tang, L., Zhang, L., Chen, X., and Yan, Y. A Specific Data Acquisition Scheme for Electrical Tomography. 2008 IEEE Instrumentation and Measurement Technology Conference. 2008. pp. 726-729.

[54] Huaxiang Wang et al. Digital signal processing in electrical capacitance tomography. APCCAS 2008 - 2008 IEEE Asia Pacific Conference on Circuits and Systems. 2008. pp. 465-468.

[55] Mohamad, E. J. et al. An introduction of two differential excitation potentials technique in electrical capacitance tomography. Sensors Actuators, A Phys. 2012. 180: 1-10.

[56] Cao, Z., Xu, L., and Wang, H. Image reconstruction technique of electrical capacitance tomography for low-contrast dielectrics using Calderon's method. Meas. Sci. Technol. 2009. 20: 104027. 